\title{
Innovative Exploration on the Practical Teaching Mode in Design under the New Normal Background
}

\author{
Yanan Yang \\ Huanghe Science and Technology College \\ Zhengzhou, China
}

\begin{abstract}
Under the new normal background, people pay more attention to diversity and personalization in their value, value of life and aesthetic value. As the backbone of the cultural and creative industry, the transformation quality of the design industry is very essential. The innovative practical teaching has become the focus of the design education in colleges and universities. According to four-year teaching goals of undergraduate program and each grade students' actual situation, three teaching modes are set in proper order in stages. In first stage (for first grade and second grade students), mainly use the traditional teaching mode; mainly use the class subject learning and problem solving mode among third grade students; for fourth grade students, mainly use the practical assignment participation and competitive program teaching; respectively strengthen and train the professional basic theory of first and second grade students, ability of thinking and analysis in design of third grade students, the practical operation ability and adaptability to changes and other comprehensive abilities of fourth grade students.
\end{abstract}

Keywords-new normal; art design; teaching mode; practical teaching; tutorial system

\section{INTRODUCTION}

Under the new normal background, the personalized and diversified consumer demand gradually becomes the mainstream consumer awareness, and the development of industries pays more attention to new technologies, new products, new formats and new business mode. The industrial organization structure tends to be small, intelligent and professional. The industrial competitiveness is gradually shifted to quality, differentiation, etc. The core of these changes is innovation. As the backbone of the cultural and creative industries, the quality and level of art and design is very essential. In this social background and development trend, colleges and universities shall carry out innovation on the development of art and design, for it has also become an unquestioned epoch topic.

In the background of the transformation, people's values, life and aesthetic values are qualitatively changing in a diversified manner, so they would view design practice in a new way. Therefore, we shall make innovation on the design teaching mode, know the new value of practice in teaching mode, and explore new teaching modes in line with the require ments of social transformation.

\section{THE ClASSIFICATION OF TEACHING MODE}

The teaching mode refers to the organizing forms in the education and teaching process and the procedures and methods in the activity process. And it is produced under certain social conditions. The teaching mode is classified into two types, the traditional teaching mode and the practical teaching mode. Only by knowing the advantages and disadvantages of these two modes, can we better use them to serve the establishment of a new teaching mode in design.

The traditional course is often carried out in a closed, static and single system. The danger of this system is that it separates thinking, experience (or hands-on operation), and the organic integrity of theory (or natural continuity). It only extracts one of the elements, or a single theoretical form to instill some static knowledge and concepts to students, or teach certain "practice" as pure technologies lacking theoretical support and thinking training significance. These isolated "course pieces" cannot provide students with a complete experience mode, nor pave a clear way for fouryear program which is to connect the program with the future career of students. As a consequence, the learning goal of students has to be reduced to the acquisition of a diploma. This phenomenon is known as the "drawback of traditional education mode".

Art design education generally has the characteristic of practice, which integrates theory and practice into an organic and mutualistic process. It is one of the differences between art design and other disciplines in undergraduate education. Practicality is the characteristic and core of design teaching mode.

Practical teaching is the general characteristic of art design education, and the most essential purpose and task of practical teaching is to cultivate students' ability to transform the external world positively. The practical teaching in undergraduate art design education can not only be understood as a simple skill, for it can help students gradually develop thinking and practical operation ability, problem solving ability in art design. We still need a variety of innovative exploration on the practical art design education. The purpose of this exploration is to gradually overcome the shortcomings of dichotomy between theory and practice and the neglect of tacit knowledge in the old education mode. 


\section{The St Aged SETTINGIN The TEACHING MODE IN DESIGN}

It is a problem we have to face to make targeted teaching mode in the teaching transformation according to different teaching purposes and tasks of four grades. The particularity of the design requires to carry out four-year teaching closely around the characteristic of practice. Practice is composed of theory, thinking and hands-on operation, which precisely shows the three teaching stages, theoretical teaching, thinking teaching, and hands-on operation teaching. According to different teaching tasks, the four-year teaching modes in design also have their own key points and purposes. The four-year teaching cycle is divided into two stages, using the traditional teaching mode in the first stage (for first grade and second grade students) and the practical teaching mode in second stage (for third and fourth grade students), to explain the teaching mode in detail.

\section{A. The Traditional Teaching Mode in the First Stage (For First Grade and Second Grade Students)}

The first and second grade students are weak in professional knowledge. It is appropriate to use the traditional teacher-centered teaching mode, for it enables students to learn ready-made theoretical knowledge. This teaching mode is based on the teacher's explanation, belonging to "direct teaching", "explicit teaching" and "active teaching". It is suitable for courses with specific content and strong structure. It takes "knowledge teaching" as the characteristic, and considers learning materials as ready-made theory knowledge to help students master the knowledge in the teaching plan step by step. In addition, it develops students' analyzing and thinking ability, deduction and reasoning ability, systematic thinking ability and knowledge-receiving ability.

Therefore, the traditional teaching mode is fit for the real situation of first and second grade students with weak knowledge reserve and single linear thinking mode, and it is beneficial to the systematic learning and mastery of theoretical knowledge. In passing the conceptual knowledge and factual knowledge, the traditional teaching mode has an irreplaceable positive role in teaching problem-solving skills or low-level skills with perfect structure compared with other teaching modes. In the traditional teaching mode, teachers should pay more attention to teaching mood, intonation, action and etc., improve self-teaching tact and personality charm, and help student master abstract theoretical concepts as soon as possible. For first and second grade students, mainly use the traditional teaching mode and class tests, course examination, note writing, paper writing, picture data collection and other specific teaching methods to strengthen students' memory of professional basic knowledge, expand and upgrade students' reading range and aes thetic level with different design cases and in different styles, laying a solid theoretical foundation for future three-year study in design.

There is no perfect teaching mode. In the traditional teaching mode the learning of theory knowledge is the main content, and the taught knowledge is generally conclusive, so it results in lack of timeliness and applicability. As students accept the ready-made conclusions, they may lose the motivation and enthusiasm for thinking and practice. So, it is not conducive to developing students' problem-solving ability and innovative ability, and practical operation ability, especially in design. Therefore, the advantages and disadvantages of the traditional teaching mode make it just suitable for first and second grade students in professional teaching.

\section{B. The Practical Teaching Mode in Second Stage (For Third and Fourth Grade Students)}

The validity of knowledge comes from the practice of teaching. For third grade and fourth grade students majoring in design, they shall pay more attention to the validity of knowledge and teachers should take "practical knowledge" as main teaching task. So we mainly use the practical teaching mode.

Practical teaching needs to be matched with practice teaching. According to Constructing Basic Mode for Developing Students' Practical Ability in China, the practical teaching can be divided into four types: the practical experience mode, the problem solving mode, the research practice mode and the project learning mode. Practice has two basic forms; one is the real and specific practical activity that has become reality; the other is practical activity in people's minds that will become reality, and it is a practical thinking ability in false state. These two forms are often used in design teaching. The former is aimed at the specific implementation of real design projects, while the later mainly emphasizes the thinking ability of design concept in virtual project. The function of practical knowledge is to accomplish the practical tasks. It has the characteristic of situationality (deciding what kind of technical rule and experience to use by judging), complexity (cannot be summarized with formula or proposition) and dynamics (can only grasp the technical rules in the process of practice). The three characteristics require students to master the creative intelligence and practical intelligence.

1)Third grade: use the class project learning and problem solving mode to train students' thinking ability in design. From two basic forms of practice and three characteristics of practical knowledge, we can see that hands-on operation is just a form of practice, not all the contents of the practice. The non-class practical teaching that only lays emphasis on going to the construction sites or design enterprises regardless of objects is not the only teaching mode. At least it is not suitable for third grade students majoring in design.

The third grade students through two years of study on theoretical knowledge (i.e. "inert knowledge", "explicit knowledge") have finish their professional basic knowledge structure. Basic knowledge is dispersed, staged and dismembered. After two years of study on basic knowledge, students may have a certain professional and theoretical foundation. But they still do not start the "learning-by-doing" practice, and have only a few opportunities to solve real problems personally. In the face of specific project, they still remain in general and one-sided level in design positioning, 
design concept and design principle, and cannot draw appropriate design ideas from learned knowledge according to individual characteristics of the project.

The educational task of third grade students is not to develop hands-on ability but practical thinking ability and ability of concrete analysis of concrete problems and the integration ability of systematic knowledge application. Therefore, we select the project learning and problem solving mode. It mainly uses classroom teaching and introduces virtual subject projects. Teachers can set some valuable questions according specific project and make a curriculum system with special design projects as elements. By assuming "autonomous design" projects, students can develop their information collection and sorting ability, analysis and summarizing ability, reflective ability and innovation ability. Finally students can construct knowledge system and design plan independently.

At the same time, this teaching mode emphasizes the plan discussion (group discussion and etc.) and plan explanation (PPT etc.), train students' communication ability, understanding ability, language expression ability and adaptable ability. It can close the distance between teaching task and the expected abilities of third grade students. First, try to associate the reflective things of learning with selfknown things, seriously think the common character and personality of these associations, and thus construct a smooth relationship between "association" and "thinking". Second, if we can combine the association and thinking process with the coordinated leaning negotiation process (i.e. the exchange and discussion process), the students will learn more effectively. Third, there are two types of negotiation, "self negotiation" and "mutual negotiation" (also known as "internal negotiation" and "social negotiation"). Self negotiation refers to the argument with self on what is right. Mutual negotiation refers to discussion and debate among study group members.

2)Fourth grade: use the practical assignment participation practice experience mode to improve students, hands-on ability. Use the competitive program research practical mode to stimulate students' innovation ability. The main task of fourth grade is to solve practical problems with learning knowledge, and carry out design, which is an inspection and verification on three years of learning knowledge and ability (including theoretical knowledge and thinking ability). It emphasizes students' hands-on ability, implementation, performance and development and other comprehensive abilities in design.

We can use the practice experience mode (real subject projects) to participate in practical as signment, and even go to design company or the construction site, and the research practice mode (competitive program) focusing on design predictability and innovation is to train and improve fourth grade students' comprehensive ability in design. Meanwhile, we can invite designers, employers and experts to guide and teach students and help them understand the design market, to achieve seamless connectivity between schools and markets.
One of the more remarkable and effective teaching methods is the tutorial system. The tutorial system is derived from the cognitive apprenticeship system, which was proposed by the American Educator Collins in 1980. The socalled tutorial system (cognitive apprenticeship system) is to combine the core content of the traditional apprenticeship system - students, under the guidance of experts or teachers, with the education mode in colleges and universities and thus form a new teaching mode. Students (Apprentice) obtain knowledge and skills through observing and imitating experts or teachers, and gradually participate into practical work in personal. It includes: how experts obtain knowledge and apply knowledge to solve real problems, how experts carry out reasoning and make strategies in solving complicated tasks.

The tutorial system focuses on the "implicit knowledge" practice and experience process that textbook and theoretical knowledge are hard to describe, and experience and wisdom hidden in the process. In the tutorial system teaching mode, students personally participate in the activities with "expert community", exchange with them about society and market, and thus learn practical knowledge. It can develop students problem solving ability, present higher-order thinking ability, and finally combine the skills and strategies with theoretical knowledge, to complete real design task. This teaching method makes up the static and closed shortcomings of the traditional education mode, and makes teaching process more flexible and diversified, and integrates all knowledge points and abilities together.

Teachers can adjust the difficulty of assignments, reset design tasks, give suggestions and design effect analysis according to students' actual situation, and thus realize the transformation "from guiding students to finish task to students finishing task independently".

It is necessary to say that the number of design experts and teachers are very limited, so work view or participation is constraint by objective circumstances. The tutorial system is more suitable for some teachers and students. But it does not affect its teaching effect. Using the minority to bring along the majority could supervise teachers and students that do not participate, and guide them to further enhance selfability and enter into the elite teaching mode, realizing self value.

\section{CONCLUSION}

No matter what teaching mode we used, the purpose is to bring students and teaching of teachers into design practice, and help students master basic knowledge. And then students can use learned knowledge to finish real subject and solve actual problems flexibly when facing specific and complicated problems (research subject and corporate project). And students can obtain comprehensive design ability and practical application ability and innovative ability

\section{REFERENCES}

[1] Zhou Hong. Teaching Methods. Beijing: Minzu University of China Press, first edition in June 2003. 
[2] Jiang Bin. Research on Overall Transformation of Main Courses Teaching Achievements of Environmental Art Design. Southern China Normal University, October 2008.

[3] Li Ruijun. Discussion on Cultivation of Environmental Art Design Talents. Journal of Nanping Teachers College, No. 3, Vol. 22, September 2003.

[4] Zhao Jian. Progressive Differences of Environmental Art Teaching Project Design. Design for China - Collected Papers of First Session National Environment Art Design Exhibition, first edition in June 2004, $154 \sim 156$ pages.

[5] Ma Kexin. Comparison of Simulation Subject Teaching and Actual Subject Teaching - Discussion on Time Feat ures of Environmental Art Design. Design for China - Collected Papers of First Session National Environment Art Design Exhibition, first edition in June 2004, $161 \sim 163$ pages. 